\title{
An ensemble study of HyMeX IOP6 and IOP7a: sensitivity to physical and initial and boundary condition uncertainties
}

\author{
A. Hally ${ }^{1}$, E. Richard ${ }^{1}$, and V. Ducrocq ${ }^{2}$ \\ ${ }^{1}$ Laboratoire d'Aérologie, UMR5560, Université de Toulouse and CNRS, Toulouse, France \\ ${ }^{2}$ CNRM, Météo-France, Toulouse, France \\ Correspondence to: A. Hally (alan.hally@meteo.fr) \\ Received: 4 November 2013 - Published in Nat. Hazards Earth Syst. Sci. Discuss.: 23 December 2013 \\ Revised: 20 March 2014 - Accepted: 24 March 2014 - Published: 9 May 2014
}

\begin{abstract}
The first Special Observation Period of the HyMeX campaign took place in the Mediterranean between September and November 2012 with the aim of better understanding the mechanisms which lead to heavy precipitation events (HPEs) in the region during the autumn months. Two such events, referred to as Intensive Observation Period 6 (IOP6) and Intensive Observation Period 7a (IOP7a), occurred respectively on 24 and 26 September over southeastern France. IOP6 was characterised by moderate to weak low-level flow which led to heavy and concentrated convective rainfall over the plains near the coast, while IOP7a had strong low-level flow and consisted of a convective line over the mountainous regions further north and a band of stratiform rainfall further east. Firstly, an ensemble was constructed for each IOP using analyses from the AROME, AROME-WMED, ARPEGE and ECMWF operational models as initial (IC) and boundary (BC) conditions for the research model Meso-NH at a resolution of $2.5 \mathrm{~km}$. A high level of model skill was seen for IOP7a, with a lower level of agreement with the observations for IOP6. Using the most accurate member of this ensemble as a CTRL simulation, three further ensembles were constructed in order to study uncertainties related to cloud physics and surface turbulence parameterisations. Perturbations were introduced by perturbing the time tendencies of the warm and cold microphysical and turbulence processes. An ensemble where all three sources of uncertainty were perturbed gave the greatest degree of dispersion in the surface rainfall for both IOPs. Comparing the level of dispersion to that of the ICBC ensemble demonstrated that when model skill is low (high) and lowlevel flow is weak to moderate (strong), the level of dispersion of the ICBC and physical perturbation ensembles is (is
\end{abstract}

not) comparable. The level of sensitivity to these perturbations is thus concluded to be case dependent.

\section{Introduction}

The Mediterranean basin is a complex geographic region prone to extreme rainfall events during the autumn months. The resulting flash floods can lead to economic damage and even fatalities (see Llasat et al., 2013 for a list of such events over the northwestern Mediterranean). Clearly these high-impact weather events need to be accurately forecast, leading to the development of dedicated international research projects. MEDEX (MEDiterranean EXperiment, http://medex.aemet.uib.es/), DRIHM (Distributed Research Infrastructure for Hydro-Meteorology, http://www. drihm.eu/) and HyMeX (HYdrological cycle in Mediterranean EXperiment, http://www.hymex.org/) are three such projects. MEDEX aims to forecast more accurately the important weather events associated with Mediterranean cyclones while simultaneously investigating the societal impacts of these events. DRIHM seeks to provide easier access to hydrometeorological data while also facilitating the collaboration between meteorologists and hydrologists with the aim of accelerating scientific advances in hydrometeorological research. Such advances will include enhanced modelling and data processing capabilities through the integration of dedicated hydrometeorological services throughout the European e-Infrastructure network. The overall aim of the HyMeX project (Drobinski et al., 2014) is to better understand and forecast the water cycle in the Mediterranean with an emphasis on intense hydrometeorological events. The first 
Special Observation Period (SOP1), which took place between September and November 2012, focused on heavy precipitation events (HPEs) in the northwestern Mediterranean. Twenty intensive observation periods (IOPs) were undertaken during the SOP1, with a survey of HPEs in Spain, France and Italy (Ducrocq et al., 2014).

In southeastern France, these HPEs develop principally associated with a large-scale upper-level trough over the North Atlantic which brings southerly low-level marine flows towards Mediterranean coastlines. These flows are laden with moisture as the sea surface temperature during the autumn months remains greater than the temperature of the surrounding land basins. When heavy rainfall accumulations are observed on the foothills of the Cévennes, deep convection is more likely to be triggered by the orography. When heavy rainfall accumulations are observed on the plains or the sea, other mechanisms of convection triggering and sustainment are suggested, such as low-level convergence reinforced by an evaporative cold pool (Bresson et al., 2012; Ducrocq et al., 2008).

Numerical weather prediction (NWP) of convective rainfall events has improved in recent years due to advances in computing power. NWP models can now run at kilometric resolutions and thus explicitly resolve the dynamics of mesoscale convective systems. However, despite this progress, limitations still apply due to the involvement of many multi-scale processes, the quick propagation of initial errors throughout the forecasting domain and the complexity in correctly simulating deep convective processes. Walser et al. (2004) and Hohenegger and Schär (2007) have investigated these issues. Walser et al. (2004) argued that the development of convective cells become increasingly difficult to predict at decreasing scales due to chaotic aspects of certain convective processes. They also showed that the growth of small-scale uncertainties and nonlinear interactions between atmospheric processes can quickly disrupt predictability. Hohenegger and Schär (2007) demonstrated that initial perturbations can disperse throughout the entire forecasting domain within a couple of hours, becoming amplified at far remote locations. Leoncini et al. (2010) suggested that the growth of the perturbation is weakly sensitive to the characteristics of the initial perturbation and that a similar value is reached at saturation, independent of the amplitude of the perturbation.

Ensemble prediction systems (EPSs) have been put forward as a suitable strategy for coping with predictability limitations (Houtekamer et al., 1996; Fritsch and Carbone, 2004). They give the probability of an event occurring by starting from a set of perturbed scenarios which represent the inherent uncertainties in the initial atmospheric state and in model parameterisations. Taking the different sources of uncertainty into account in an ensemble design is a challenge, as the uncertainties can depend upon the biases of the computational model and on the situation under examination. Ducrocq et al. (2008) showed that for HPEs in the south of France the mi- crophysical processes were important factors which can control the stationarity of a mesoscale convective system (MCS). An accurate description of these processes is thus imperative. As they occur at sub-grid resolutions, they must be parameterised, which introduces a level of uncertainty in their representation. Many studies have attempted to examine the issues related to physical parameterisation uncertainties. Houtekamer et al. (1996), Buizza et al. (1999) and Stensrud et al. (2000) were some of the first to construct ensemble simulations using perturbed physical processes. Different methodologies have been employed, ranging from the use of different physical parameterisation schemes to stochastic perturbations applied upon the time tendencies of physical processes. More recently, Gebhardt et al. (2011), Clark et al. (2011), Bouttier et al. (2012), Fresnay et al. (2012), Leoncini et al. (2013) and Hally et al. (2013) constructed convection-permitting short-range ensembles. The existence of such a breath of ensemble methodologies demonstrates that the most suitable approach remains open to debate, as no one methodology is found to be superior to the others.

Increases in model resolution have also brought to light the uncertainties associated with the parameterisation of boundary layer turbulence (Bryan et al., 2003; Fiori et al., 2010). The rainfall field and the evolution of convective systems have been shown to be sensitive to its representation. Wisse and de Arellano (2004), Wyngaard (2004) and Honnert et al. (2011) also demonstrated that at a kilometric resolution, the use of 1-D turbulence closure methods is questionable, while the formulation used in large eddy simulations (LES) is not appropriate.

The present work uses the methodology described in Hally et al. (2013) and inspired by the previous works of Buizza et al. (1999) and Fresnay et al. (2012). These studies described ensemble simulations using stochastic perturbations upon the physical processes. Hally et al. (2013) and Fresnay et al. (2012) concentrated on errors associated with the boundary layer turbulence and warm microphysical processes. They investigated the possible use of ensembles containing perturbations upon these processes in the forecasting of HPEs in the Mediterranean region. The aim of the present study is to extend this methodology to include perturbations upon the cold microphysical processes, which can also have an impact upon convective storm development (Gilmore et al., 2004; Richard et al., 2003; Lascaux et al., 2006). Secondly, the sensitivity of the simulated rainfall field to perturbations upon the physical processes is compared to the sensitivity introduced by modifying the initial (IC) and boundary (BC) conditions. Studies from both the COSMO and AROME communities (Peralta et al., 2012; Kühnlein et al., 2014; Vié et al., 2011, 2012) demonstrated that the simulation of precipitation events is quite sensitive to perturbations upon the IC and BC. Vié et al. $(2011,2012)$ in particular investigated the impact of IC and BC uncertainties upon Mediterranean HPE simulations and illustrated that the rainfall development displays a more important level of 
sensitivity to errors in the IC and $\mathrm{BC}$ than to errors in the physical parameterisations. This hypothesis will also be scrutinised within the scope of this study.

The layout of the paper is as follows: an introduction of the chosen case studies, the reasons for their selection and the large-scale atmospheric conditions under which they developed are described in Sect. 2, along with a description of the model set-up and an explanation of the configuration of the different ensembles. Section 3 presents the results of the physical perturbation and IC and BC perturbation ensembles for each case study. A comparison and discussion of the level of dispersion and the sensitivity of the rainfall field to the different perturbations is given in Sect. 4. Summaries and conclusions of the paper's main results are outlined in Sect. 5.

\section{Description of cases, model set-up and configuration of ensembles}

\subsection{Description of cases}

The two heavy rainfall episodes that were chosen for this study are HyMeX IOP6 and IOP7a which occurred on 24 and 26 September 2012 respectively. Both were extensively measured and observed at the time and represent two of the most significant rainfall episodes to have taken place within France during the HyMeX SOP1 campaign.

\subsubsection{IOP6}

On the evening of 23 September 2012, an upper-level trough was observed over western Europe (see Fig. 1a). This was associated with a low-pressure system which was situated to the northwest of Ireland and led to convectively inducive low-level conditions. Surface winds from the southwest brought moist air sweeping in from the Mediterranean as shown by the plots of $10 \mathrm{~m}$ wind and potential temperature at $950 \mathrm{hPa}$ in Fig. 1b. These conditions instigated the development of an intense and fast-moving convective line which caused approximately $100 \mathrm{~mm}$ rainfall in the $24 \mathrm{~h}$ period between 00:00 UTC on 24 September and 00:00 UTC on 25 September. Most of the precipitation fell during the $6 \mathrm{~h}$ window between 00:00 UTC and 06:00 UTC on 24 September with observed intensities of up to 50 or $60 \mathrm{~mm}$ per hour. The heaviest rainfall was organised in a southwest to northeasterly line extending from the northern Gard department into the Drôme department (see Fig. 2 for location of important geographical features and French departments). Soundings taken at the Nîmes station gave a CAPE value of $57 \mathrm{~J} \mathrm{~kg}^{-1}$ at 00:00 UTC on the 24 September and a value of $176 \mathrm{~J} \mathrm{~kg}^{-1}$ at 06:00 UTC on the 24 September.

\subsubsection{IOP7a}

In the early hours of 26 September, the low-pressure system had propagated eastwards and was now centred over
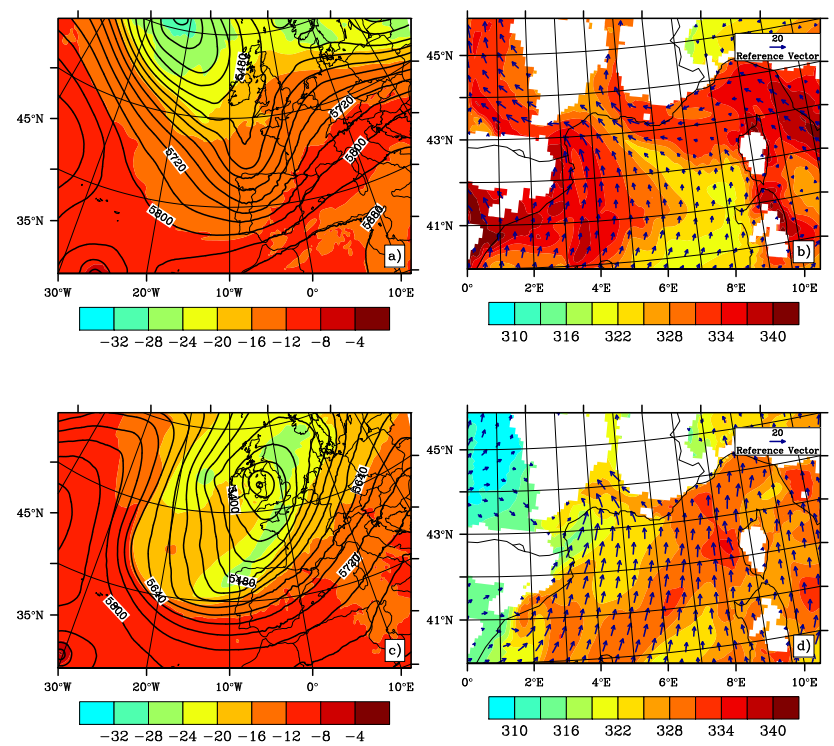

Fig. 1. ECMWF large-scale analysis at 18:00 UTC on 23 September 2012 showing (a) temperature $\left({ }^{\circ} \mathrm{C}\right)$ and geopotential height $(\mathrm{m})$ at $500 \mathrm{hPa}$ and $(\mathrm{b})$ potential temperature $(\mathrm{K})$ and winds $\left(\mathrm{m} \mathrm{s}^{-1}\right)$ at $950 \mathrm{hPa}$. Identical plots for 26 September 2012 at 00:00 UTC are given in (c) and (d).

the British Isles (see Fig. 1c). The upper-level trough deepened and began to edge its way in over France as the day progressed. This brought moderate to strong south to southeasterly flow in over the southern regions of France. These winds were laden with warm moist air, picked up as they passed over the relatively warm Mediterranean Sea (Fig. 1d). This led to the development of a mesoscale convective system in the early morning over the Ardèche and Gard regions as the warm unstable air converged. A cold front associated with the low-pressure system further to the north approached the area during the afternoon, merged with the convective system and moved eastwards as evening arrived. Upwards of $100 \mathrm{~mm}$ of rain was observed during the $24 \mathrm{~h}$ period between 00:00 UTC on 26 September and 00:00 UTC on 27 September. The majority of the rain fell over the Ardèche department but the Drome also experienced accumulations of up to $75 \mathrm{~mm}$ in $24 \mathrm{~h}$. The Nîmes sounding taken at 12:00 UTC on 26 gave a CAPE value of $109 \mathrm{~J} \mathrm{~kg}^{-1}$.

\subsection{Model set-up}

The French research model Meso-NH (Mesoscale NonHydrostatic model, Lafore et al., 1998, http://mesonh.aero. obs-mip.fr/mesonh) was used to conduct the simulations presented in this study. Meso-NH was developed jointly by the Laboratoire d'Aérologie (LA) and the Centre National de Recherches Métérologiques (CNRM) and it shares the same set of physical parameterisations as the operational model of Météo-France, AROME. The turbulence scheme follows the work of Cuxart et al. (2000) while the radiation fluxes 


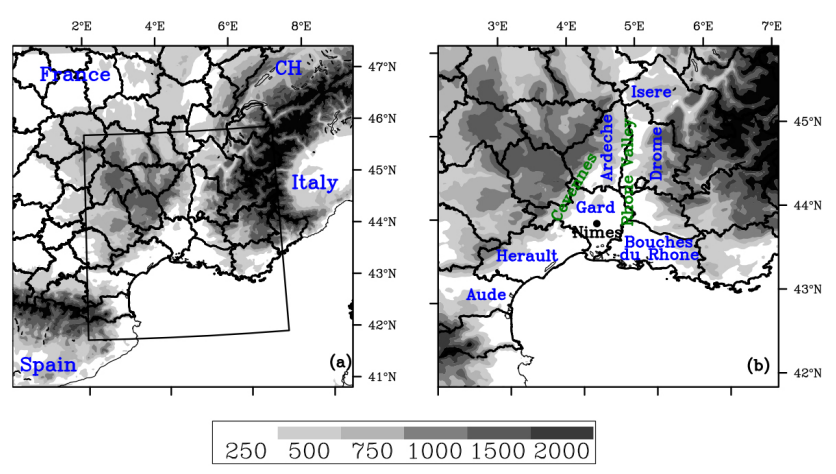

Fig. 2. (a) Map of the domain of southern France used for the simulations. The area under the solid line, referred to as the target area in the text, is enlarged in (b). All simulation statistics are performed over the domain in (b). Shading represents altitudes over $250 \mathrm{~m}$. Geographical names and French administrative regions are recalled, in particular seven départements of the southern France region which are given in blue. Two important geographical features, the Cévennes mountain ranges and the Rhône Valley, are indicated in green. The location of the Nîmes sounding is also given for reference.

are calculated using the Rapid Radiative Transfer Model (Mlawer et al., 1997). Shallow convection is parameterised according to Pergaud et al. (2009) while for the purposes of this study the deep convection scheme is deactivated as the simulations are performed at a convection-resolving resolution. Six water species (vapour, cloud water, rainwater, primary ice, snow aggregates and graupel) are prognosis variables whose equations are managed by the ICE3 bulk microphysical scheme of Pinty and Jabouille (1998). The exchanges of energy at the surface are represented according to four possible surface types (natural surfaces, urban areas, oceans and lakes). The ISBA (Interactions Soil-BiosphereAtmosphere scheme Noilhan and Mafhouf, 1996) is used for natural land surfaces.

The grid spacing used for the simulations here presented is that of the Météo-France operational forecasting model AROME, or $2.5 \mathrm{~km}$. The simulated area covers a $288 \times 288$ point domain located over southern France and the northwestern Mediterranean (see Fig. 2 for description of domain). All of the simulations described were performed over $24 \mathrm{~h}$ periods. For IOP6, the maximum observed rainfall occurred at 02:00 UTC on 24 September. In order to avoid the influence of spin-up errors, simulations for this case were initialised at 18:00 UTC on 23 September. For IOP7a, the maximum observed rainfall occurred at 08:00 UTC on 26 September. The simulations were initialised at 00:00 UTC on 26 September allowing sufficient time before the onset of convection and for the dissipation of model spin-up errors.
Table 1. Characteristics of the different ensembles.

\begin{tabular}{lccccc}
\hline $\begin{array}{l}\text { Ensemble } \\
\text { name }\end{array}$ & $\begin{array}{c}\text { Case } \\
\text { study }\end{array}$ & $\begin{array}{c}\text { ICBC } \\
\text { pertur- } \\
\text { bations }\end{array}$ & $\begin{array}{c}\text { Warm } \\
\text { perts. }\end{array}$ & $\begin{array}{c}\text { Warm } \\
\text { and } \\
\text { cold } \\
\text { perts. }\end{array}$ & $\begin{array}{c}\text { Warm, } \\
\text { cold and } \\
\text { turbulent } \\
\text { perts. }\end{array}$ \\
\hline ICBC6 & IOP6 & $\checkmark$ & & & \\
ICBC7a & IOP7a & $\checkmark$ & & & \\
WA6 & IOP6 & & $\checkmark$ & & \\
WC6 & IOP6 & & $\checkmark$ & $\checkmark$ & \\
MT6 & IOP6 & & $\checkmark$ & $\checkmark$ & $\checkmark$ \\
WA7a & IOP7a & & $\checkmark$ & & \\
WC7a & IOP7a & & $\checkmark$ & $\checkmark$ & \\
MT7a & IOP7a & & $\checkmark$ & $\checkmark$ & $\checkmark$ \\
\hline
\end{tabular}

\subsection{Configuration of ensembles}

Four ensembles were constructed for each convective episode, the characteristics and details of which are given in Tables 1 and 2. The first ensemble (which will be labelled ICBC(6)(7a), with the 6 and 7a representing either IOP6 or IOP7a) contained four members. Each of the members was given a different set of initial (IC) and boundary conditions (BC) derived from the ECMWF/IFS and Météo France/ARPEGE, AROME and AROME-WMED analysis. The AROME and AROME-WMED analysis files are available every $3 \mathrm{~h}$ compared to every $6 \mathrm{~h}$ for the ARPEGE and ECMWF outputs. The AROME and AROME-WMED files are available at the same $2.5 \mathrm{~km}$ resolution that was used within this study. AROME covers the region of Metropoli$\tan$ France with further details of the model available in Seity et al. (2011). AROME-WMED, designed especially for HyMeX, is similar to AROME but takes in a larger geographical region including the western half of the Mediterranean Sea. ARPEGE runs at a $10.5 \mathrm{~km}$ resolution over France while the horizontal resolution of the ECMWF mesh size is approximately $16 \mathrm{~km}$. No intermediary downscaling step was performed between these resolutions and that of the $2.5 \mathrm{~km}$ resolution employed by the Meso-NH model. Each member was run over the periods described in Sect. 2.2.

The second ensemble WA(6)(7a), the 6 and 7a again representing either IOP6 or IOP7a, was constructed of 11 members: ten perturbed members and one control (CTRL) member. The most skillful member of the $\operatorname{ICBC}(6)(7 a)$ ensemble was used as the CTRL member. Here the definition of skillful is the ensemble member which modelled the observed rainfall in the most realistic and statistically satisfying manner. Simple statistical tests such as correlation with observed values, standard deviation and root mean squared error (RMSE) were used to determine this statistical skill. For the other ten members, the time tendencies of the warm rain processes of the ICE3 microphysical scheme were perturbed by a random factor ranging between 0.5 and 1.5. This random factor was generated in the same manner as in Hally et al. (2013) 
Table 2. Processes perturbed in the 6(7a)WA and 6(7a)WC ensembles.

\begin{tabular}{lcc}
\hline Processes perturbed & $\begin{array}{c}\text { WA } \\
\text { ensemble }\end{array}$ & $\begin{array}{c}\text { WC } \\
\text { ensemble }\end{array}$ \\
\hline Autoconversion of cloud drops to raindrops & $\checkmark$ & $\checkmark$ \\
Accretion of cloud droplets by raindrops & $\checkmark$ & $\checkmark$ \\
Evaporation of raindrops & $\checkmark$ & $\checkmark$ \\
Autoconversion of ice particles to snow particles & & $\checkmark$ \\
Vapour deposition on snow and graupel & & $\checkmark$ \\
Light and heavy riming of snow aggregates and graupel & & $\checkmark$ \\
Accretion of rain and aggregates & & $\checkmark$ \\
Dry and wet growth of graupel & & $\checkmark$ \\
Melting of snow aggregates and graupel & & $\checkmark$ \\
\hline
\end{tabular}

and Fresnay et al. (2012). Each random factor multiplied simultaneously the sources and sinks of a given microphysical process to ensure mass conversation was met. For the third ensemble $(\mathrm{WC}(6)(7 \mathrm{a}))$, perturbations were performed upon the cold microphysical processes as well as the warm processes. The ensemble had the same CTRL simulation as the WA ensemble and also contained 10 perturbed members. A unique random factor was generated for each cold process. The fourth and final ensemble (MT(6)(7a)) consisted in adding perturbations to the turbulent parameterisation time tendencies, while simultaneously maintaining the perturbations upon the warm and cold microphysical processes. Perturbations were introduced upon the turbulent tendencies in the same manner as was done for the warm and cold processes and as is also described in Hally et al. (2013). As for the WA(6)(7a) and WC(6)(7a) ensembles, the ensemble consisted of a CTRL member and ten perturbed members.

\section{Ensemble simulations}

\subsection{IOP6}

\subsubsection{ICBC ensemble}

The simulated rainfall for each member of the ICBC6 ensemble is shown in Fig. 4 with the corresponding observed rainfall amounts displayed in Fig. 3a. The signal of the convective system can be seen forming a southwest to northeasterly line from the Gard department into the Ardèche department. The AROME forced simulation (Fig. 4a) simulates the heaviest rainfall to the north of the convective line over the ridges of the Cévennes mountain ranges. Over the areas of the observed maxima (upwards of $75 \mathrm{~mm}$ ) simulated accumulations only reach values of between 20 and $40 \mathrm{~mm}$. This is however the most accurate representation of the convective system of all the four members. The AROME-WMED member simulates the precipitation maxima over the Cévennes ridges, as in the AROME member, but also produces rainfall to the northeast of the convective line over the central Ardèche. The localisation of the convective line is almost
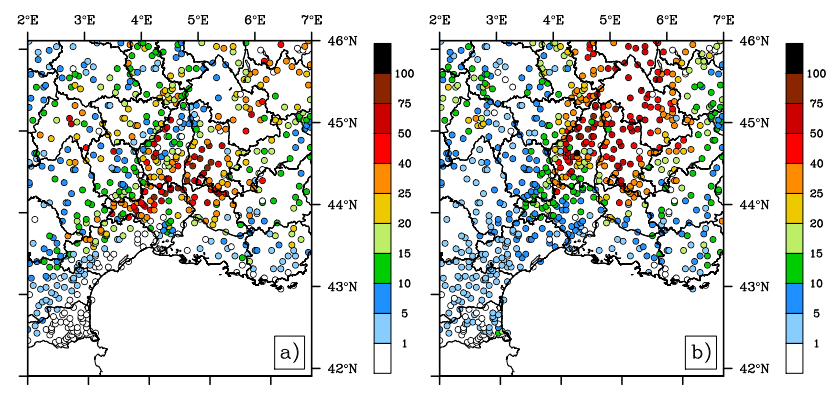

Fig. 3. The rainfall amounts (in $\mathrm{mm}$ ) observed at Météo France stations between 18:00 UTC on 23 September and 18:00 UTC on 24 September (a) and between 00:00 UTC on 26 September and 00:00 UTC on 27 September (b).

completely missed by the ECMWF member simulation as it places a large rainfall maximum to the northeast of the Cévennes Mountains. The ARPEGE member produces no discernible maximum but does succeed in finding the northeastern tail of the convective line over the Ardèche albeit with less accumulated rainfall than was observed. Overall, three out of the four sets of initial and boundary conditions (AROME, AROME-WMED, ARPEGE) succeed in localising the rainfall over the southwestern Ardèche but fail to simulate the correct intensities. The AROME member most accurately captures the convective line over the western and northern Gard, while all other members fail to simulate it correctly.

Figure 5 shows a time series of the hourly accumulated rainfall averaged over the model domain. The peak in observed precipitation occurred at 02:00 UTC. This peak is missed by all simulations, regardless of their initial and boundary conditions The AROME simulation is closest in terms of timing and averaged rainfall amounts with a difference of $3 \mathrm{~h}$ between the simulated and observed maxima. The AROME-WMED, ECMWF and ARPEGE members of the ensemble present less accurate representations of the observed maximum but simulate more accurately the second peak at 07:00 UTC. 


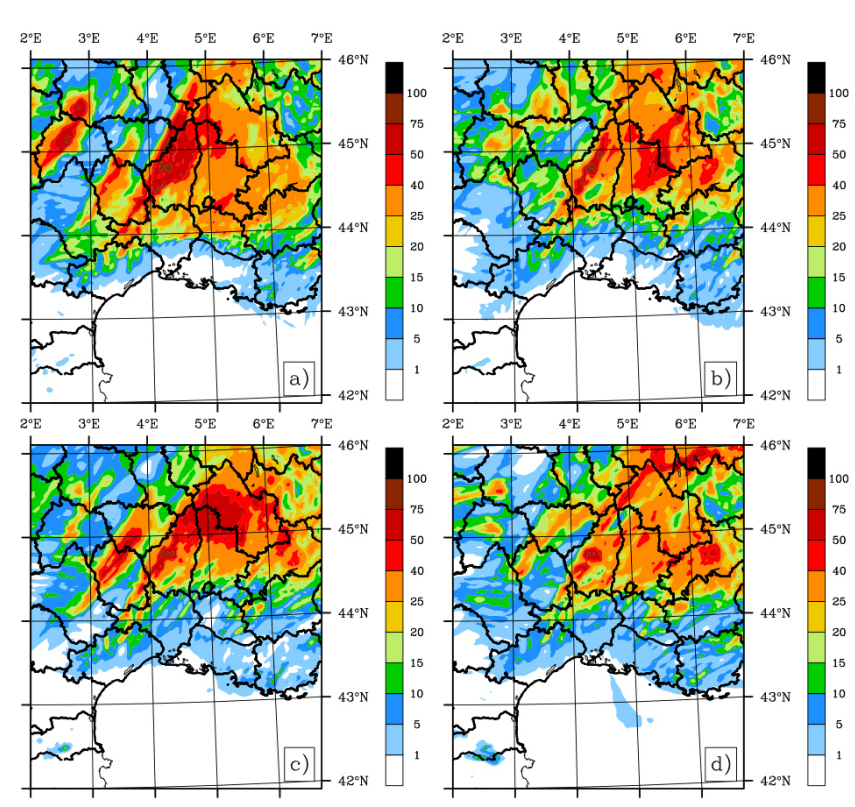

Fig. 4. The simulated daily rainfall amounts (in $\mathrm{mm}$ ) between 18:00 UTC on 23 September and 18:00 UTC on 24 September for the AROME (a), AROME-WMED (b), ECMWF (c) and ARPEGE (d) members of the ICBC6 ensemble.

The Taylor diagram for the ICBC ensemble is presented in Fig. 6. The AROME member presents a spatial correlation of 0.45 with the observations, as do the AROMEWMED and ARPEGE simulations. The AROME member gives a normalised standard deviation of almost 1 . Taylor (2001) defines this normalised standard deviation as a ratio of the modelled over the observed variability. According to this definition, one could say that the AROME simulation describes most accurately the level of observed dispersion. The AROME-WMED and ARPEGE members give lower standard deviations illustrating their weaker degree of dispersion. The RMSE, shown on the Taylor diagram as the distance between the model point and the REF point, illustrates that the AROME-WMED and ARPEGE members are slightly more accurate than the AROME member. However, the improved spatial correlation, normalised standard deviation and the fact that the AROME member captures most accurately the observed peak were judged to be more important measures of statistical skill.

Concluding from Figs. 4-6, a hierarchy of forecasting accuracy is deduced for this case. The AROME simulation is deemed the most accurate at representing the observed rainfall pattern as it is the only member of the ensemble to simulate the amplitude of the observed peak. The AROME member also gave the highest spatial correlation and was quite accurate in forecasting the observed rainfall variability. The AROME-WMED and ARPEGE rainfall representations are similar but the AROME-WMED member simulates the rainfall intensities more accurately. The ECMWF mem- ber gives the least realistic rainfall localisation and evolution, as it completely misses the convective activity in the northern Gard.

\subsubsection{Physical process ensembles}

The AROME simulation from the ICBC6 was thus chosen as the CTRL simulation to which the members of the WA6, WC6 and MT6 ensembles were compared. The Taylor diagram for each of these ensembles is presented in Fig. 7. Examining the diagram for the WA6 ensemble, some members show increased spatial correlation with the observations compared to the CTRL simulation. The most correlated member now has a correlation of 0.55 compared to 0.45 for the CTRL. Spread between the ensemble members is more remarkable in the differing spatial correlation values than in the normalised standard deviation values as most members retain a value of 1.0. This would suggest that the perturbations impact more strongly upon the localisation of the simulated rainfall rather than upon the intensity. In comparison with WA6, WC6 has more members with lower spatial correlation. There is little increase in spread between the members of the WC6 ensemble, suggesting that the sensitivity of the surface rainfall field to these processes is small. A comparison of the WA6 and MT6 ensembles shows that adding in perturbations to the turbulent time tendencies does increase dispersion. The range of spatial correlation values for the members of the MT6 ensemble extends from 0.4 to 0.6 with the normalised standard deviations varying between 0.75 and 1.0. Thus simultaneously perturbing the cold and warm microphysical and turbulent processes impacts upon the spatial localisation and intensity of the surface rainfall field.

Figure 8 shows the mean and standard deviation from the $24 \mathrm{~h}$ accumulated surface rainfall for each of the WA6, WC6 and MT6 ensembles. The standard deviation signal for the WA6 and WC6 ensembles are similarly weak. Some spread is seen in the eastern Gard and to the east of the Cévennes mountain ridges where the heaviest rain was simulated. Little dispersion is seen over the mountain ridges, which indicates that in these areas, the rainfall field is very weakly controlled by the microphysical processes. The standard deviation signal for the MT6 ensemble shows a larger degree of dispersion, especially in the southwestern Ardèche where strong convective activity was observed. This increase in dispersion for the MT6 ensemble compared to the WA6 and WC6 ensembles would indicate that the rainfall field is more sensitive to boundary layer turbulence perturbations than to perturbations upon the microphysical processes. Compared to the WA6 and WC6 ensembles, MT6 shows increased dispersion over the mountainous ridges. However, like WA6 and WC6, the strongest standard deviation values are located east of the Cévennes. 


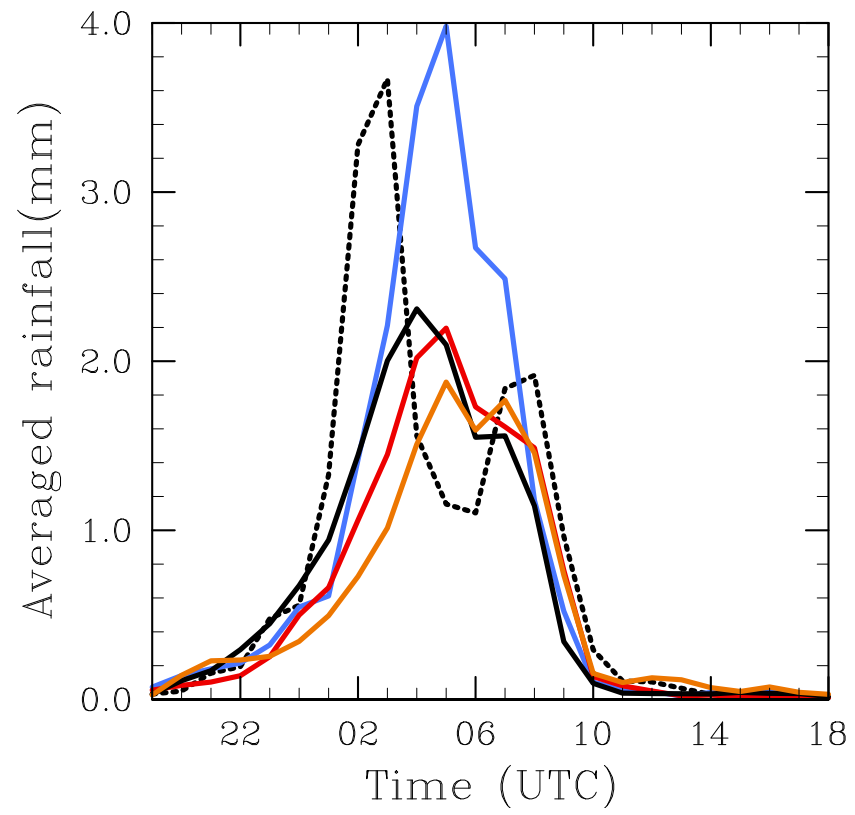

Fig. 5. Temporal evolution of the spatially averaged hourly accumulation for each member of the ICBC6 ensemble between 18:00 UTC on 23 September and 18:00 UTC on 24 September. The AROME member appears in blue, the AROME-WMED member in red, the ECMWF member in black and the ARPEGE member in orange. The black dotted line represents the evolution of the observed rainfall.

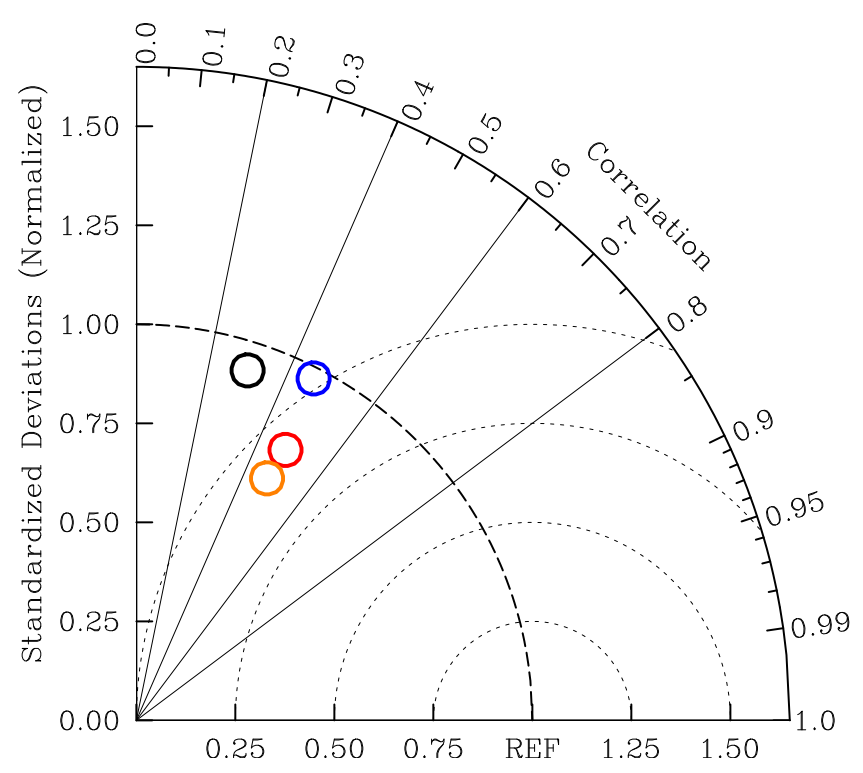

Fig. 6. $24 \mathrm{~h}$ Taylor diagram for the ICBC6 ensemble showing the spatial correlation, standard deviation and RMSE of the simulated accumulated rainfall with the observed rainfall for the AROME (blue circle), AROME-WMED (red circle), ECMWF (black circle) and ARPEGE (orange circle) members of the ensemble.

\subsection{IOP7a}

\subsubsection{ICBC ensemble}

The simulated rainfall for each member of the ICBC7a ensemble is illustrated in Fig. 9 with the corresponding observations being displayed in Fig. 3b. In contrast with the convective line seen in IOP6, the precipitation of IOP7a fell mainly over the mountainous regions in the Cévennes area. Although convective initiation was the result of a convergent air mass, the orography played a substantial role in the evolution and sustainability of the convective system. As mentioned in the case description, this convective line merged with a cold front which arrived from the west during the afternoon of 26 September and then propagated eastwards, which led to a second rainfall maximum concentrated mainly over the Ardèche and Isère departments. The model performs much more accurately for this case than for the IOP6 with all sets of initial and boundary conditions capturing the convective line. The AROME member (Fig. 9a) simulates quite well the rainfall over the mountainous areas with accumulations of between 75 and $100 \mathrm{~mm}$ corresponding well with the observed values. The AROME-WMED member (Fig. 9b) gives the least accurate representation as it shifts the convective line eastwards away from the mountainous regions. The simulated rainfall values do not compare as well as the AROME member with the observed values as maxima remained between 50 and $75 \mathrm{~mm}$. An investigation of the state of the large-scale dynamics present in the initial conditions for this case (not shown) indicates that the aforementioned cold front arrived in over the target area too early in the AROME-WMED conditions, thus preventing the convective system from fully developing and pushing the heaviest of the rainfall eastwards. The ECMWF member also performs well in localising the rainfall pattern but tends to over-forecast the rainfall amounts, with a simulated maximum of $194 \mathrm{~mm}$ vs. an observed maximum of $100 \mathrm{~mm}$. The ARPEGE member succeeds in simulating the rainfall pattern over the mountain ranges but in contrast with the ECMWF member the simulated values were less than what was observed.

The temporal evolution of the instantaneous rainfall for the ICBC7a ensemble is presented in Fig. 10. In general, all of the ensemble members succeed in reproducing the observed rainfall evolution. As for the ICBC6 ensemble, the AROME member gives the most accurate description of the evolution, successfully capturing both the precipitation peak at $8 \mathrm{~h}$ after initialisation time or 08:00 UTC and the peak at $17 \mathrm{~h}$ after initialisation time or 17:00 UTC. The over-forecasting in the ECMWF simulation is not as clear on this plot but the simulated rainfall does exceed the observed one between 10:00 and 13:00 UTC. The AROME-WMED member produces a very weak signal for the first observed peak at 08:00 UTC which corresponds with its inaccuracy in forecasting the most convectively active period of the system. The weak ARPEGE accumulations are also easily visible on this plot. 


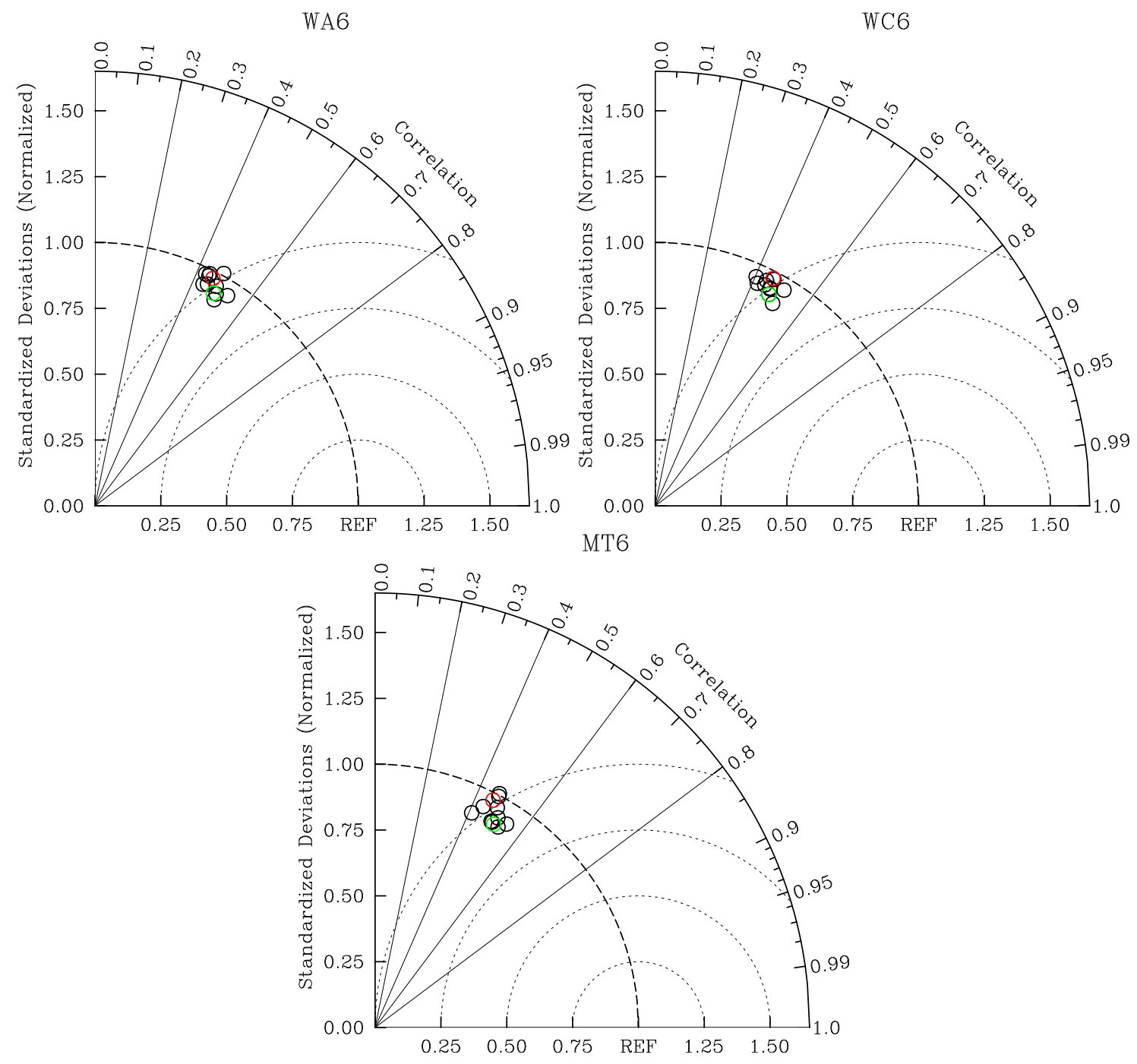

Fig. 7. As Fig. 6 except for the WA6, WC6 and MT6 ensembles. The CTRL simulation is given in red, the ensemble members in black and the ensemble mean in green.

The Taylor diagram in Fig. 11 confirms the increase in forecasting skill of the different sets of conditions for this case compared to IOP6. Both the AROME and ECMWF members present a spatial correlation of 0.8 . The ECMWF member gives a normalised standard deviation value of almost 1.25 indicating the over-forecasting of the rainfall compared to the observed values. Like the IOP6 case, the AROME member gives a normalised standard deviation value close to 1.0 demonstrating that of the four sets of conditions, it gave the most realistic description of the observed variability. The AROME-WMED member shows the lowest spatial correlation owing largely to its misplacement of the convective system. The ARPEGE member's normalised standard deviation was close to 0.5 indicating this simulation's inability to model the observed variability.
These plots show that as for the previous case of the IOP6, a hierarchy of forecasting accuracy is present. The AROME forced member of the ensemble gave the most accurate representation of the rainfall field, resulting in a high spatial correlation and a favourable normalised standard deviation value. Also, its temporal evolution followed the observed evolution quite adeptly. The ECMWF member simulation gave a good spatial localisation of the convective system but gives a slight over-forecast of the rainfall intensity. The AROME-WMED and ARPEGE members give weaker rainfall accumulations with the ARPEGE member slightly outperforming the AROME-WMED member in terms of spatial localisation. 

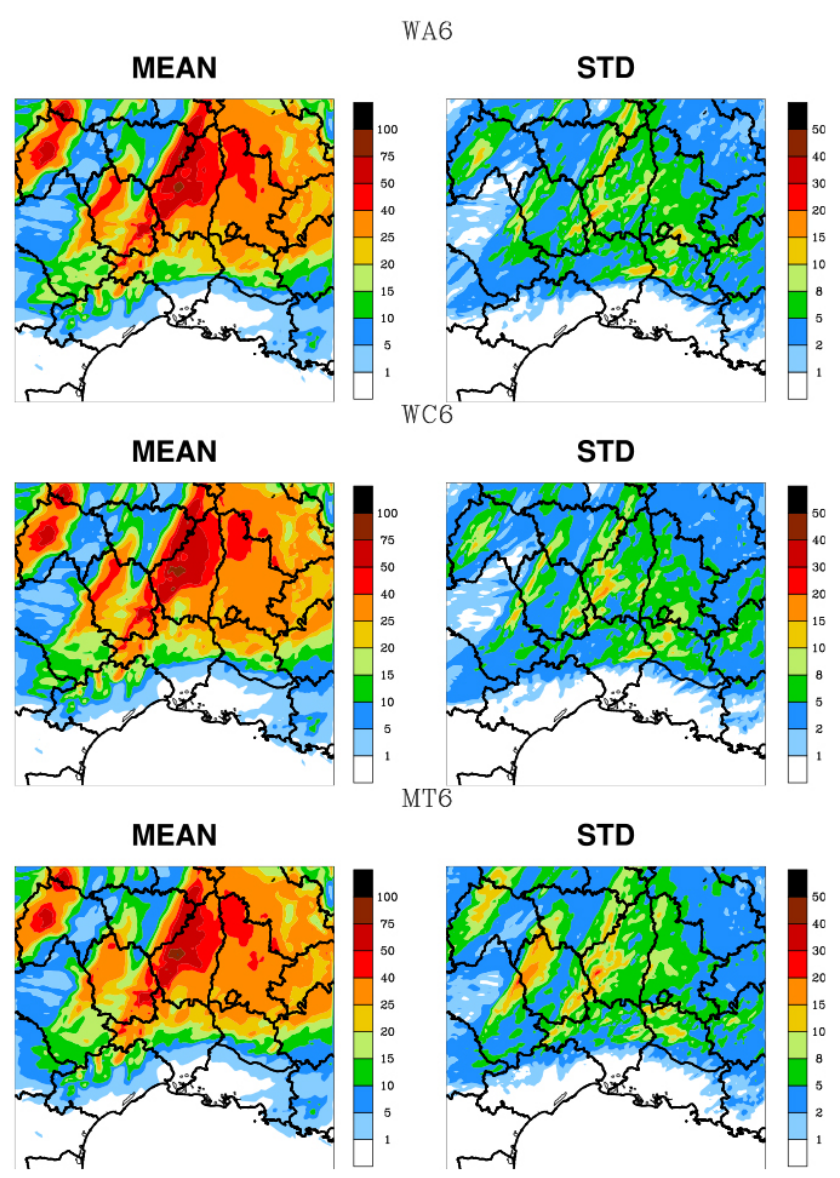

Fig. 8. Mean and standard deviation of the $24 \mathrm{~h}$ accumulated rainfall for the WA6 (top), WC6 (middle) and MT6 (bottom) ensembles.

\subsubsection{Physical process ensembles}

The ensembles WA7a, WC7a and MT7a were constructed using the AROME member of the ICBC7 ensemble as a CTRL. The Taylor diagram for each ensemble is shown in Fig. 12. Very little dispersion is produced between the members of the WA7a ensemble. All members maintain the spatial correlation of 0.8 that the CTRL simulation presented, with slight differences appearing in the standard deviation values. This lack of spread in the members' representation of the rainfall underlines the small role played by the microphysical processes for this case. Adding cold process perturbations to those of the warm processes does little to change the ensemble spread as the Taylor diagram for WC7a illustrates. Examining the Taylor diagram for MT7a, there is a significant increase in dispersion between the members compared to the WA7a and WC7a ensembles. The correlation now ranges from 0.7 to approximately 0.85 . The normalised standard deviation values are also much more dispersed than for the WA7a and WC7a ensembles.

The mean and standard deviation plots for the rainfall field are given in Fig. 13. These plots reinforce the results gleamed
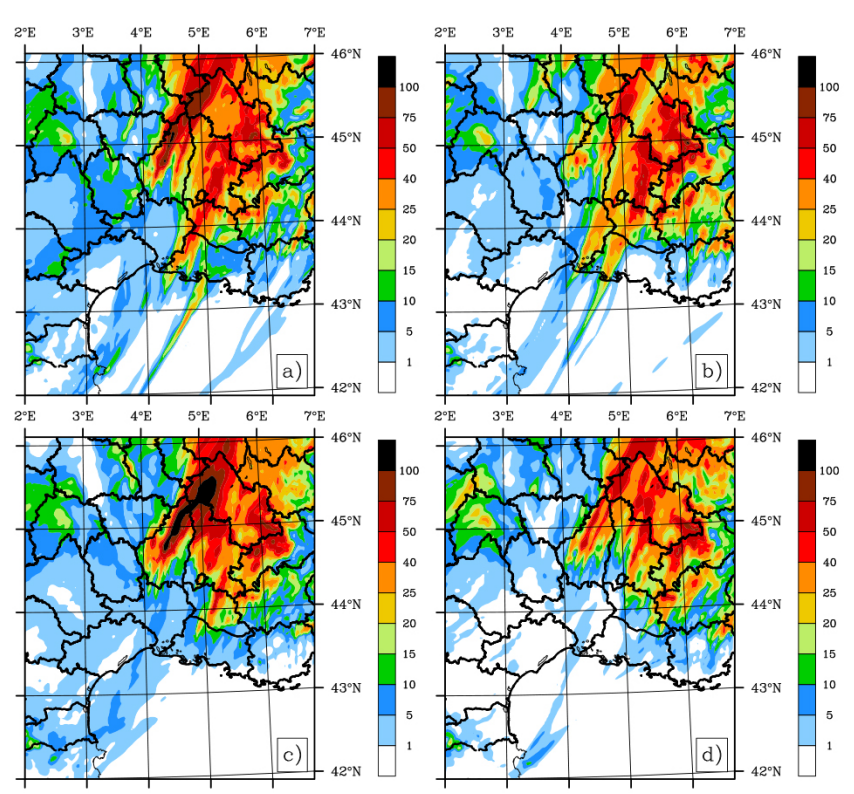

Fig. 9. The simulated daily rainfall amounts (in $\mathrm{mm}$ ) between 00:00 UTC on 26 September and 00:00 UTC on 27 September for the AROME (a), AROME-WMED (b), ECMWF (c) and ARPEGE (d) members of the ICBC7a ensemble.

from the Taylor diagrams. Little if any deviation from the mean is produced by the WA7a and WC7a ensembles. Comparatively the MT7a ensemble displays a much stronger standard deviation signal. This is most clearly in evidence in the northern Ardèche region where some of the heaviest rain fell. Deviation from the mean can also be seen to the south and further eastwards where the less convectively intense rainfall occurred. This ensemble even presents some dispersion over the mountainous regions, although the most significant spread occurs just to the east of the Cévennes.

One member in particular (displayed in blue on the MT7a ensemble) separates itself quite distinctly from the other members. Investigating the perturbations introduced for this member shows that the value of the turbulent time tendencies was cut by $50 \%$, the graupel melting process was at $80 \%$ of its original value, while the evaporation process was decreased by $40 \%$. The members' spatial correlation decreased from 0.8 to less than 0.7 between the WA7a and MT7a ensembles due to the effect of these perturbations. However, this change in spatial correlation was not observed between the WA7a and WC7a ensembles, indicating that the turbulence perturbations were responsible for the modification in the simulated rainfall. A plot of the horizontal flow along the mountainous regions (not shown) illustrates that the turbulence perturbations change the interaction of the flow with the local orography, and thus displace the point of convective initiation. Vertical velocity plots (also not shown) indicate that the turbulence perturbations also led to weaker convective updrafts and thus weaker accumulated rainfall amounts. 


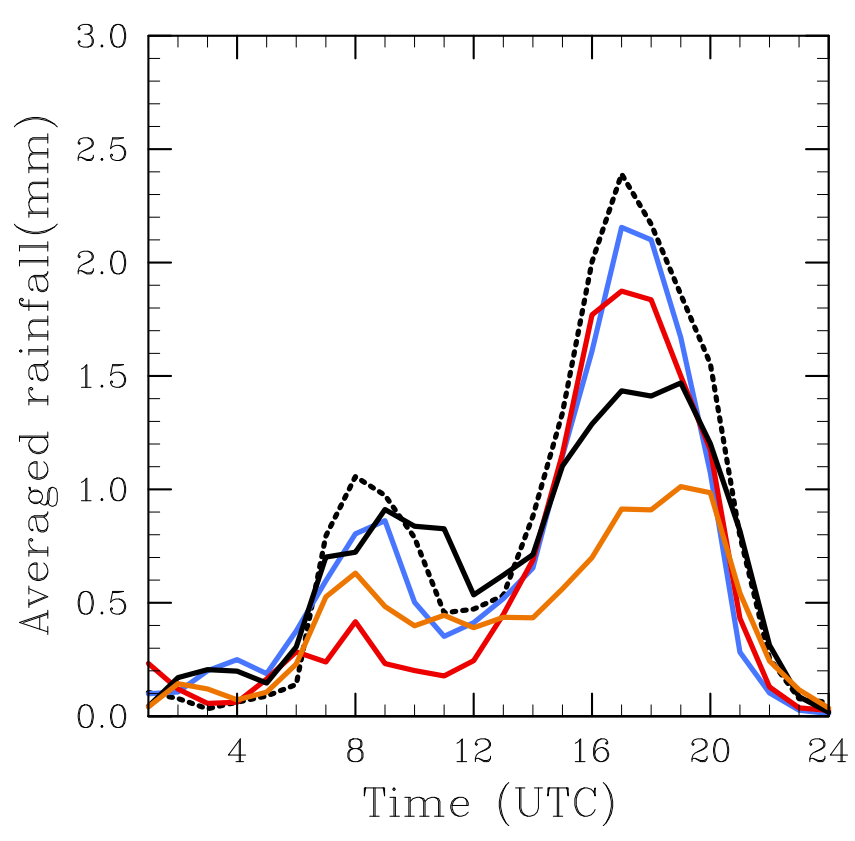

Fig. 10. Temporal evolution of the spatially averaged hourly accumulation of the rainfall field for each member of the ICBC7a ensemble between 00:00 UTC on 26 September and 00:00 UTC on 27 September. The AROME member appears in blue, the AROMEWMED member in red, the ECMWF member in black and the ARPEGE member in orange. The black dotted line represents the evolution of the observed rainfall field.

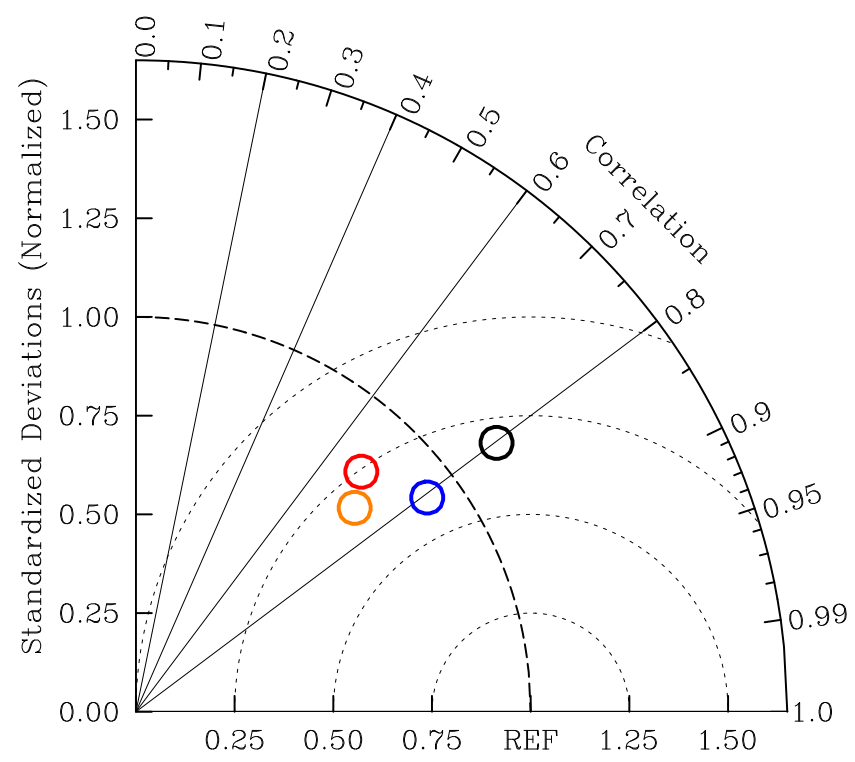

Fig. 11. $24 \mathrm{~h}$ Taylor diagram for the ICBC7a ensemble showing the spatial correlation, standard deviation and RMSE of the simulated rainfall with the observed rainfall for the AROME (blue circle), AROME-WMED (red circle), ECMWF (black circle) and ARPEGE (orange circle) members of the ensemble.
This may lead to the conclusion that such perturbation configurations should be avoided as they lead to a decrease in model skill. However, the set of perturbation coefficients employed for MT6 were identical. The member of MT6 which experienced blue member perturbations gives an increase in spatial correlation (not shown) between WC6 and MT6. This underlines the case dependency of these types of perturbation.

\section{Sensitivity in the different ensembles}

Comparisons between the dispersion induced by changing IC and $\mathrm{BC}$ and modifying the physical parameterisations are drawn from the Taylor diagrams in Figs. 6, 7, 11, and 12 and the mean and standard deviation of rainfall plots in Figs. 8, 13 and 14 . Clearly there is a greater degree of dispersion for the WA6, WC6 and MT6 ensembles compared to the WA7a, WC7a and MT7a ensembles. This agrees with the results reported in Hally et al. (2013), Fresnay et al. (2012) and Stensrud et al. (2000), where the authors illustrate that sensitivity to perturbations upon physical processes is case dependent. Hally et al. (2013) demonstrated that the sensitivity of Mediterranean HPE simulations to physical perturbations is dependent upon the model skill and the strength of the lowlevel flow. IOP6 and IOP7a confirm this tendency.

Ensembles with changing IC and BC do not show this tendency. Examining the Taylor diagrams in Figs. 6 and 11 shows that both ensembles display similar levels of dispersion. The ICBC7a ensemble gives a larger range of standard deviation values, which is confirmed by the plots in Fig. 14, with the ICBC7a demonstrating a large deviation from the mean for the convective rainfall pattern. This contrasts to the weaker deviation exhibited by the ICBC6 ensemble over the convective rainfall region. This seems to suggest that the IC and $\mathrm{BC}$ were more important to the development of the convective rainfall in IOP7a than in IOP6.

For IOP6, the most dispersive physical ensemble, MT6, displays a degree of dispersion comparable to that of ICBC6. The mean and standard deviation plots in Figs. 8 and 14 underline this most evidently. However, the ICBC and physical process ensembles differ as to where the deviation from the mean is located. The MT6 ensemble shows a greater level of dispersion over the regions of convective rainfall compared to the ICBC6 ensemble, suggesting an enhanced role in the development of this rainfall pattern for the physical processes over the IC and BC. For IOP7a, the physical process ensembles display a lesser degree of dispersion compared to the ICBC ensemble. A comparison of the plots in Figs. 13 and 14 illustrates this quite clearly. Apart from the MT7a ensemble, the physical process ensembles do not demonstrate any significant deviation from the mean rainfall pattern. Contrastingly, the ICBC7a ensemble gives a large area of dispersion over the Ardèche, where the convective rainfall was observed, and also further to the east, where the stratiform 


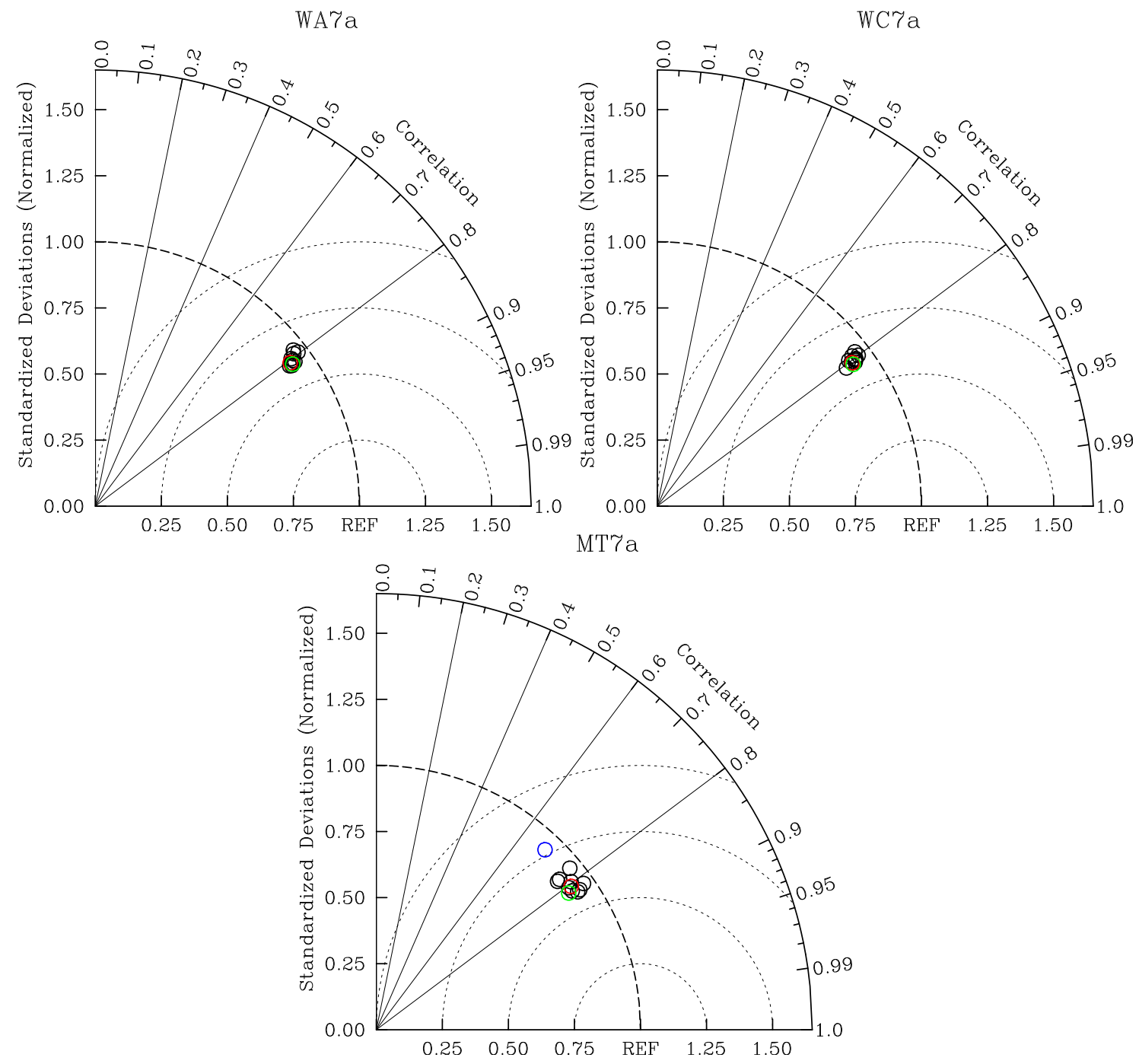

Fig. 12. As Fig. 11 except for the WA7a, WC7a and MT7a ensembles. The CTRL simulation is given in red, the ensemble members in black and the ensemble mean in green.

peak occurred. This again underlines the more important role of the IC and BC conditions in the development of IOP7a compared to the physical processes. The patterns exhibited in these ensembles seem to suggest that when the model skill is low (low-level flow is moderate - IOP6), the sensitivity of the rainfall pattern to physical and ICBC perturbations is comparable, but that when the model skill is high (low-level flow is strong - IOP7a), the rainfall pattern is more sensitive to ICBC perturbations.

\section{Conclusion and perspectives}

Southeastern France experiences heavy precipitation events (HPEs) during the months of September to November each year. These HPEs can lead to devastating flash-flood events causing economic damage and even loss of human life. IOP6 and IOP7a of the HyMeX SOP1 are two good examples of the meteorological conditions in which these events occur. IOP6 occurred in the presence of moderate to weak low-level flow from the southeast bringing moist air in over the cooler land basins. This led to the development of a convective rainfall event on the coastal plains which peaked at 02:00 UTC. IOP7a occurred under the influence of a large upper-level trough to the west of the target area, which led to strong lowlevel flow from the south-east over the Mediterranean Sea. This moist flow converged, triggering convective precipitation, with the convective updrafts further enhanced by the local orography. A peak in convective precipitation was seen at 08:00 UTC for this case. A second peak was observed at 17:00 UTC, associated with a cold front which moved in over the target area during the afternoon of IOP7a. 


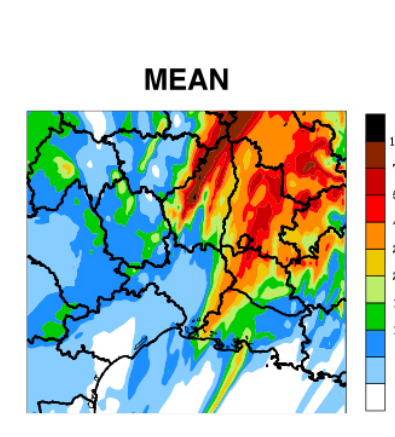

WA7a
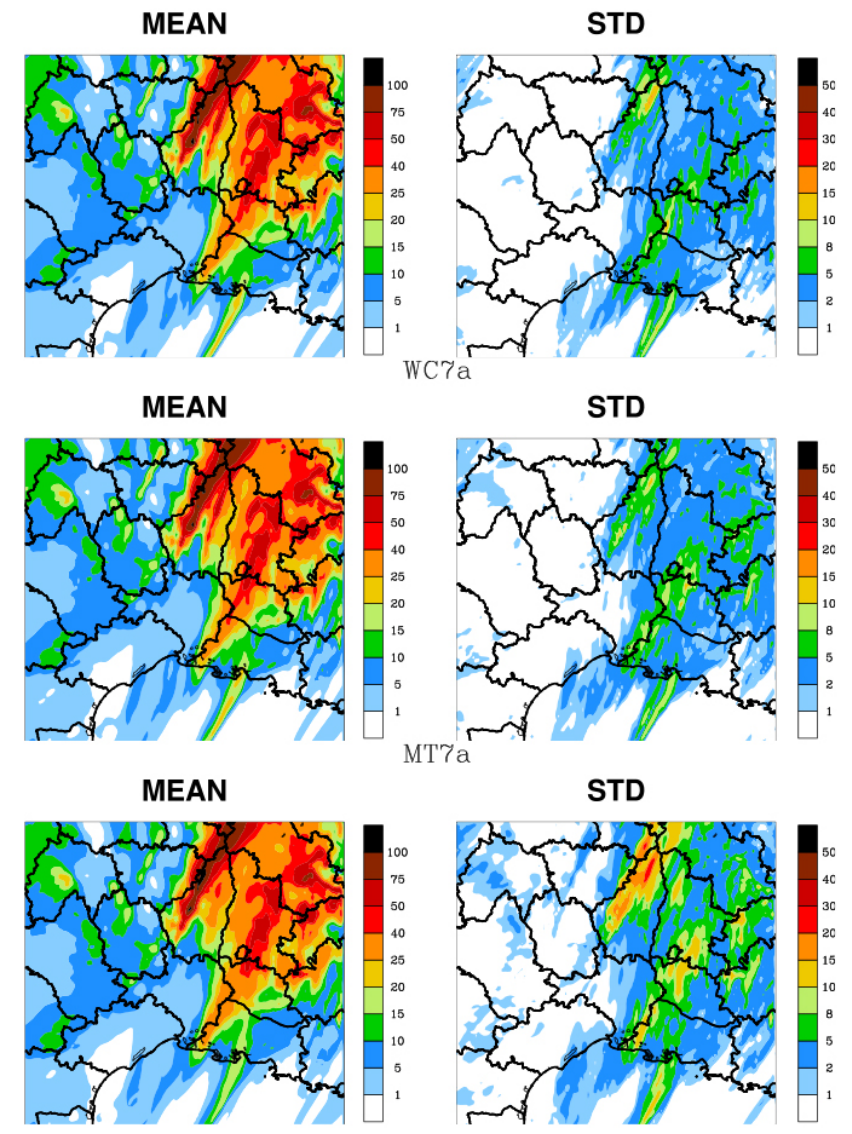

Fig. 13. Mean and standard deviation of the $24 \mathrm{~h}$ accumulated rainfall for the WA7a (top), WC7a (middle) and MT7a (bottom) ensembles.

An ensemble of simulations using different initial (IC) and boundary $(\mathrm{BC})$ conditions was constructed for each of these cases with analysis files from the AROME, AROMEWMED, ECMWF and ARPEGE models. This ensemble aimed to uncover the most accurate control (CTRL) simulation for each of the cases and to measure the sensitivity to IC and BC modifications. Temporal evolution plots and simple statistical comparisons demonstrated that the level of dispersion induced in the surface rainfall by simultaneously changing the IC and BC was similar for both cases. A CTRL simulation with IC and BC from the analysis of the AROME forecasting model displayed the most realistic representation of the observed rainfall field for both cases.

Starting from this CTRL simulation, ensembles were constructed in order to represent sources of error inherent in the model parameterisations. Particular attention was paid to the microphysical and boundary layer turbulence processes with random perturbations introduced upon the parameterised time tendencies of these processes. For IOP6, an ensemble where solely the warm microphysical processes were perturbed led to moderate dispersion in the rainfall
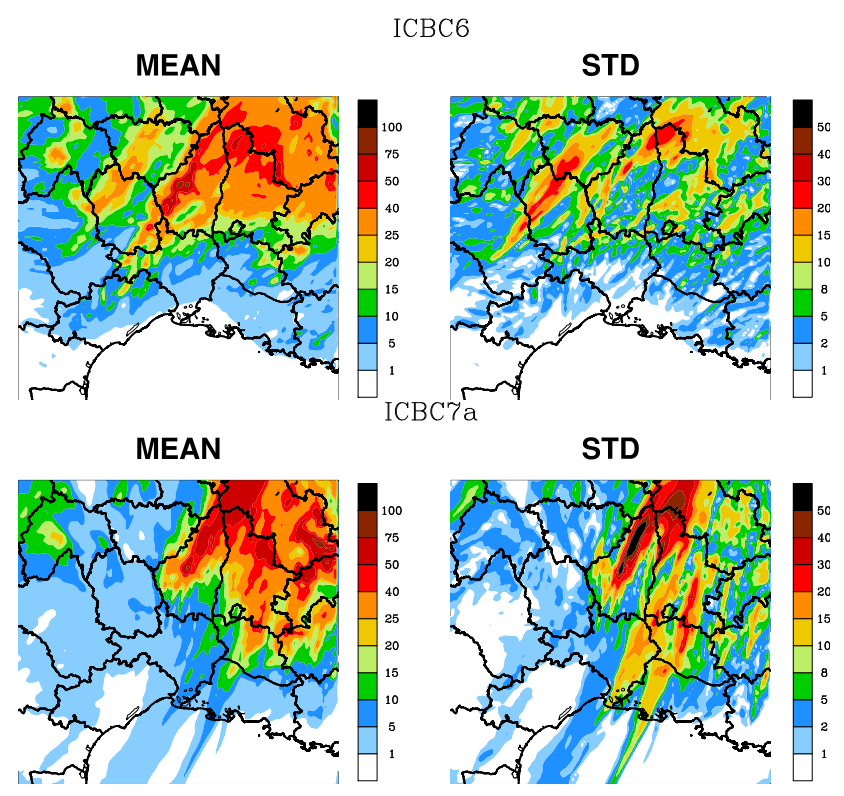

Fig. 14. Mean and standard deviation of the $24 \mathrm{~h}$ accumulated rainfall for the ICBC6 (top) and ICBC7a (bottom) ensembles.

field. Little sensitivity was demonstrated when perturbations were added to the microphysical cold processes. However, introducing perturbations upon the turbulence time tendencies led to a more significant increase in dispersion, especially over regions where the most convective rainfall occurred. For IOP7a, the level of sensitivity to physical perturbations was less than that of IOP6. As for IOP6, the rainfall pattern displayed an increased sensitivity to perturbations upon the turbulent time tendencies than upon the microphysical tendencies.

Comparisons between the ICBC and physical process ensembles showed that for IOP6, the area of convective rainfall was less sensitive to modifications in the IC and BC than to perturbations upon the physical processes. This was not the case for IOP7a, where the rainfall pattern, convective and stratiform, demonstrated a much larger degree of sensitivity to changing IC and $\mathrm{BC}$. These comparisons illustrate that for HPEs which have weak to moderate low-level flow (and thus convective initiation upstream of the orography) and low model skill (IOP6), the level of dispersion introduced in the rainfall pattern by ICBC or physical process perturbations is comparable. Concurrently, when the HPE develops in the presence of strong low-level flow (and thus convective initiation due to orographic lifting) and high model skill (IOP7a), the level of dispersion related to ICBC modifications is greater.

The ensembles presented in this study indicate that the sensitivity to perturbations upon the physical processes and IC and BC is case dependent. The relative importance of each source of error depends on the nature of the rainfall pattern and on the atmospheric conditions in which the precipitation 
event develops. This confirms the results reported in the previous studies of Hally et al. (2013) and Fresnay et al. (2012) and also complements the recent work of Keil et al. (2014), who described the increased impact of physics perturbations in the case of a weakly forced heavy rainfall event. However, further work is needed to investigate the relative contribution of the IC and $\mathrm{BC}$ to the rainfall pattern for these types of HPEs.

Both cases presented within this study developed under strong synoptic-forcing, thus indicating a larger contribution from the atmospheric rather than the surface conditions. For weakly forced Mediterranean HPEs, the specific influence of surface conditions deserves further examination. This would highlight the importance of the surface processes to the development of the rainfall pattern and would thus permit the construction of ensemble simulations which directly target the error related to the representation of such processes (Lebeaupin et al., 2006; Barthlott and Kalthoff, 2011).

Acknowledgements. This work is a contribution to the HyMeX programme supported by the CNRS, Météo-France, CNES, IRSTEA and INRA, through the meta-programme MISTRALS (Mediterranean Integrated STudies at Regional And Local Scales) dedicated to the understanding of the Mediterranean Basin environmental processes (http://www.mistrals-home.org). This work was also carried out within the framework of the DRIHM project. The authors acknowledge Météo France and the HyMeX database for supplying the observational data. Computational resources were allocated by Grand Equipement National de Calcul Intensif (GENCI project 2013010569) and Calcul en Midi Pyrenees (CALMIP, project P1247).

Edited by: C. Ramis

Reviewed by: two anonymous referees

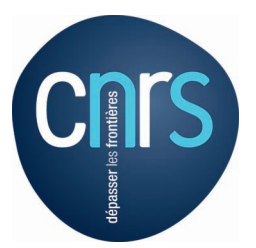

The publication of this article is financed by CNRS-INSU.

\section{References}

Barthlott, C. and Kalthoff, N.: A numerical sensitivity study on the impact of soil moisture on convection-related parameters and convective precipitation over complex terrain, J. Atmos. Sci., 68, 2971-2987, 2011.

Bouttier, F., Vie, B., Nuissier, O., and Raynaud, L.: Impact of stochastic physics in a convection-permitting ensemble, Mon. Weather Rev., 140, 3706-3721, 2012.

Bresson, E., Ducrocq, V., Nuissier, O., Ricard, D., and de SaintAubin, C.: Idealized numerical simulations of quasi-stationary convective systems over the Northwestern Mediterranean complex terrain, Q. J. Roy. Meteor. Soc., 138, 1751-1763, 2012.
Bryan, G. H., Wyngaard, J. C., and Fritsch, J. M.: Resolution requirements for the simulation of deep moist convection, Mon. Weather Rev., 131, 2394-2416, 2003.

Buizza, R., Miller, M., and Palmer, T. N.: Stochastic representation of model uncertainties in the ECMWF Ensemble Prediction System, Q. J. Roy. Meteor. Soc., 125, 2887-2908, 1999.

Clark, A. J., Kain, J. S., Stensrud, D. J., Xue, M., Kong, F., Coniglio, M. C., Thomas, K. W., Wang, Y., Brewster, K., Gao, J., Wang, X., Weiss, S. J., and Du, J.: Probabilistic precipitation forecast skill as a function of ensemble size and spatial scale in a convection-allowing ensemble, Mon. Weather Rev., 139, 14101418, 2011.

Cuxart, J., Bougeault, P., and Redelsperger, J.-L.: A turbulence scheme allowing for mesoscale and large-eddy simulations, Q. J. Roy. Meteor. Soc., 126, 1-30, 2000.

Drobinski, P., Ducrocq, V., Alpert, P., Anagnostou, E., Béranger, K., Borga, M., Braud, I., Chanzy, A., Davolio, S., Delrieu, G., Estournel, C., Filali Boubrahmi, N., Font, J., Grubisic, V., Gualdi, S., Homar, V., Ivancan-Picek, B., Kottmeier, C., Kotroni, V., Lagouvardos, K., Lionello, P., Llasat, M., Ludwig, W., Lutoff, C., Mariotti, A., Richard, E., Romero, R., Rotunno, R., Roussot, O., Ruin, I., Somot, S., Taupier-Letage, I., Tintore, J., Uijlenhoet, R., and Wernli, H.: HyMeX, a 10-year multidisciplinary program on the Mediterranean water cycle, B. Am. Meteorol. Soc., doi:10.1175/BAMS-D-12-00242.1, in press, 2014.

Ducrocq, V., Nuissier, O., Ricard, D., Lebeaupin, C., and Thouvenin, T.: A numerical study of three catastrophic precipitating events over southern France, II: Mesoscale triggering and stationarity factors, Q. J. Roy. Meteor. Soc., 134, 131-145, 2008.

Ducrocq, V., Braud, I., Davolio, S., Ferretti, R., Flamant, C., Jansa, A., Kalthoff, N., Richard, E., Taupier-Letage, I., Ayral, P., Belamari, S., Berne, A., Borga, M., Boudevillain, B., Bock, O., Boichard, J., Bouin, M., Bousquet, O., Bouvier, C., Chiggiato, J., Cimini, D., Corsmeier, U., Coppola, L., Cocquerez, P., Defer, E., Delanoë, J., Di Girolamo, P., Doerenbecher, A., Drobinski, P., Dufournet, Y., Fourrié, N., Gourley, J., Labatut, L., Lambert, D., Le Coz, J., Marzano, F., Molinié, G., Montani, A., Nord, G., Nuret, M., Ramage, K., Rison, B., Roussot, O., Said, F., Schwarzenboeck, A., Testor, P., Van, J., Vincendon, B., Aran, M., and Tamayo, J.: HyMeX-SOP1, the field campaign 1 dedicated to heavy precipitation and flash flooding in the northwestern Mediterranean, B. Am. Meteorol. Soc., doi:10.1175/BAMS-D12-00244.1, in press, 2014.

Fiori, E., Parodi, A., and Siccardi, F.: Turbulence closure parameterization and grid spacing effects in simulated supercell storms, J. Atmos. Sci., 67, 3870-3890, doi:10.1175/2010JAS3359.1, 2010.

Fresnay, S., Hally, A., Garnaud, C., Richard, E., and Lambert, D.: Heavy precipitation events in the Mediterranean: sensitivity to cloud physics parameterisation uncertainties, Nat. Hazards Earth Syst. Sci., 12, 2671-2688, doi:10.5194/nhess-12-26712012, 2012.

Fritsch, J. M. and Carbone, R. E.: Improving quantitative precipitation forecasts in the warm season: a USWRP research and development strategy, B. Am. Meteorol. Soc., 85, 955-965, 2004.

Gebhardt, C., Theis, S. E., Paulat, M., and Bouallegue, Z. B.: Uncertainties in COSMO-DE precipitation forecasts introduced by model perturbations and variation of lateral boundaries, Atmos. Res., 100, 168-177, 2011. 
Gilmore, M. S., Straka, J. M., and Rasmussen, E. N.: Precipitation uncertainty due to variations in precipitation particle parameters within a simple microphysics scheme, Mon. Weather Rev., 132, 2610-2627, 2004.

Hally, A., Richard, E., Fresnay, S., and Lambert, D.: Ensemble simulations with perturbed physical parameterisations: pre-HyMeX case studies, Q. J. Roy. Meteor. Soc., doi:10.1002/qj.2257, in press, 2013.

Hohenegger, C. and Schär, C.: Predictability and error growth dynamics in cloud-resolving models, J. Atmos. Sci., 64, 44674478, 2007.

Honnert, R., Masson, V., and Couvreux, F.: A diagnostic for evaluating the representation of turbulence in atmospheric models at the kilometric scale, J. Atmos. Sci., 68, 3112-3131, 2011.

Houtekamer, P., Lefaivre, L., Derome, J., Ritchie, H., and Mitchell, H.: A system simulation approach to ensemble prediction, Mon. Weather Rev., 124, 1225-1242, 1996.

Keil, C., Heinlein, F., and Craig, G. C.: The convective adjustement time-scale as indicator of predictability of convective precipitation, Q. J. Roy. Meteor. Soc., 140, 480-490, doi:10.1002/qj.2143, 2014.

Kühnlein, C., Keil, C., Craig, G. C., and Gebhardt, C.: The impact of downscaled initial condition perturbations on convectivescale ensemble forecasts of precipitation, Q. J. Roy. Meteor. Soc., doi:10.1002/qj.2238, in press, 2014.

Lafore, J. P., Stein, J., Asencio, N., Bougeault, P., Ducrocq, V., Duron, J., Fischer, C., Héreil, P., Mascart, P., Masson, V., Pinty, J. P., Redelsperger, J. L., Richard, E., and VilàGuerau de Arellano, J.: The Meso-NH Atmospheric Simulation System. Part I: adiabatic formulation and control simulations, Ann. Geophys., 16, 90-109, doi:10.1007/s00585-997-0090-6, 1998.

Lascaux, F., Richard, E., and Pinty, J.-P.: Numerical simulations of three different MAP IOPs and the associated microphysical processes, Q. J. Roy. Meteor. Soc., 132, 1907-1926, 2006.

Lebeaupin, C., Ducrocq, V., and Giordani, H.: Sensitivity of torrential rain events to the sea surface temperature based on highresolution numerical forecasts, J. Geophys. Res., 111, D12110, doi:10.1029/2005JD006541, 2006.

Leoncini, G., Plant, R. S., Gray, S. L., and Clark, P. A.: Perturbation growth at the convective scale for CSIP IOP18, Q. J. Roy. Meteor. Soc., 136, 653-670, 2010.

Leoncini, G., Plant, R. S., Gray, S. L., and Clark, P. A.: Ensemble forecasts of a flood-producing storm: comparison of the influence of model-state perturbations and parameter modifications, Q. J. Roy. Meteor. Soc., 139, 198-211, 2013.

Llasat, M. C., Llasat-Botija, M., Petrucci, O., Pasqua, A. A., Rosselló, J., Vinet, F., and Boissier, L.: Towards a database on societal impact of Mediterranean floods within the framework of the HYMEX project, Nat. Hazards Earth Syst. Sci., 13, 13371350, doi:10.5194/nhess-13-1337-2013, 2013.
Mlawer, E. J., Taubman, S. J., Brown, P. D., Iacono, M. J., and Clough, S. A.: Radiative transfer for inhomogeneous atmospheres: RRTM, a validated corrolated-k model for the longwave, J. Geophys. Res., 102, 16663-16682, 1997.

Noilhan, J. and Mafhouf, J.: The ISBA land surface parameterisation, Global Planet. Change, 13, 145-159, 1996.

Peralta, C., Bouallegue, Z. B., Theis, S. E., Gebhardt, C., and Buchold, M.: Accounting for initial condition uncertainties in COSMO-DE-EPS, J. Geophys. Res., 117, D07108, doi:10.1029/2011JD016581, 2012.

Pergaud, J., Masson, V., Malardel, S., and Couvreux, F.: A parameterization of dry thermals and shallow cumuli for mesoscale numerical weather prediction, Bound.-Lay. Meteorol., 132, 83106, 2009.

Pinty, J.-P. and Jabouille, P.: A mixed-phase cloud parameterization for use in a mesoscale non-hydrostatic model: simulations of a squall line and of orographic precipitations, in: Tenth AMS Cloud Physics Conference, 17-21 August, American Meteorological Society, Everett, WA, USA, 217-220, 1998.

Richard, E., Cosma, S., Tabary, P., Pinty, J. P., and Hagen, M.: Highresolution numerical simulations of the convective system observed in the Lago Maggiore area on 17 September 1999 (MAP IOP 2a), Q. J. Roy. Meteor. Soc., 129, 543-563, 2003.

Seity, Y., Brousseau, P., Malardel, S., Hello, G., Benard, P., Bouttier, F., Lac, C., and Masson, V.: The AROME-France Convective-Scale Operational Model, Mon. Weather Rev., 139, 976-991, 2011.

Stensrud, D., Bao, J., and Warner, T.: Using initial conditions and model physics perturbations in short-range ensemble simulations of mesoscale convective systems, Mon. Weather Rev., 128, 2077-2107, 2000.

Taylor, K. E.: Summarizing multiple aspects of model performance in a single diagram, J. Geophys. Res., 106, 7183-7192, 2001.

Vié, B., Nuissier, O., and Ducrocq, V.: Cloud-resolving ensemble simulations of Mediterranean heavy precipitating events: uncertainty on initial conditions and lateral boundary conditions, Mon. Weather Rev., 139, 403-423, 2011.

Vié, B., Molinié, G., Nuissier, O., Vincendon, B., Ducrocq, V., Bouttier, F., and Richard, E.: Hydro-meteorological evaluation of a convection-permitting ensemble prediction system for Mediterranean heavy precipitating events, Nat. Hazards Earth Syst. Sci., 12, 2631-2645, doi:10.5194/nhess-12-2631-2012, 2012.

Walser, A., Luthi, D., and Schar, C.: Predictability of precipitation in a cloud-resolving model, Mon. Weather Rev., 132, 560-577, 2004.

Wisse, J. S. P. and Vilà-Guerau de Arellano, J.: Analysis of the role of the planetary boundary layer schemes during a severe convective storm, Ann. Geophys., 22, 1861-1874, doi:10.5194/angeo22-1861-2004, 2004.

Wyngaard, J. C.: Toward numerical modeling in the "terra incognita”, J. Atmos. Sci., 61, 1816-1826, 2004. 